\title{
Estimation of country-specific and global prevalence of male circumcision
}

\author{
Brian J Morris ${ }^{1}$, Richard G Wamai ${ }^{*}$, Esther B Henebeng ${ }^{3}$, Aaron AR Tobiann ${ }^{4}$, Jeffrey D Klausner ${ }^{5}$, Joya Banerjee ${ }^{6}$ \\ and Catherine A Hankins ${ }^{7,8}$
}

\begin{abstract}
Background: Male circumcision (MC) status and genital infection risk are interlinked and MC is now part of HIV prevention programs worldwide. Current $M C$ prevalence is not known for all countries globally. Our aim was to provide estimates for country-specific and global MC prevalence.

Methods: MC prevalence data were obtained by searches in PubMed, Demographic and Health Surveys, AIDS Indicator Surveys, and Behavioural Surveillance Surveys. Male age was $\geq 15$ years in most surveys. Where no data were available, the population proportion whose religious faith or culture requires $M C$ was used. The total number of circumcised males in each country and territory was calculated using figures for total males from (i) 2015 US Central Intelligence Agency (CIA) data for sex ratio and total population in all 237 countries and territories globally and (ii) 2015 United Nations (UN) figures for males aged 15-64 years.
\end{abstract}

Results: The estimated percentage of circumcised males in each country and territory varies considerably. Based on (i) and (ii) above, global MC prevalence was $38.7 \%$ (95 \% confidence interval [Cl]: 33.4, 43.9) and $36.7 \%$ (95\% Cl: $31.4,42.0)$. Approximately half of circumcisions were for religious and cultural reasons. For countries lacking data we assumed $99.9 \%$ of Muslims and Jews were circumcised. If actual prevalence in religious groups was lower, then MC prevalence in those countries would be lower. On the other hand, we assumed a minimum prevalence of $0.1 \%$ related to MC for medical reasons. This may be too low, thereby underestimating MC prevalence in some countries.

Conclusions: The present study provides the most accurate estimate to date of MC prevalence in each country and territory in the world. We estimate that 37-39 \% of men globally are circumcised. Considering the health benefits of MC, these data may help guide efforts aimed at the use of voluntary, safe medical MC in disease prevention programs in various countries.

Keywords: Male circumcision, Global prevalence, Country-specific prevalence, Population health

\section{Background}

The circumcision of males is one of the most common surgical procedures in the world. It may also be one of the oldest, likely predating recorded human history [1]. While religious and cultural considerations are a major reason behind the practice, a growing volume of research attests to the significant medical and public health benefits of male circumcision (MC) [2-5]. Health, medical, sexual, and cosmetic benefits may explain why $\mathrm{MC}$ is a fundamentally inherent part of diverse human

\footnotetext{
* Correspondence: r.wamai@neu.edu

${ }^{2}$ Department of African-American Studies, Northeastern University, Boston, MA 02115, USA

Full list of author information is available at the end of the article
}

cultures globally, especially in hot arid environments [1] In light of the protection that MC affords against HIV infection in particular [6], major health bodies such as the World Health Organization (WHO), the Joint United Nations Program on HIV/AIDS (UNAIDS), and the US Centers for Disease Control and Prevention (CDC) have endorsed and currently promote voluntary medical MC (VMMC) in HIV-1 epidemic settings in which the major route of HIV transmission is through heterosexual intercourse [7, 8]. In sub-Saharan African countries, 13 were prioritized by WHO and UNAIDS for VMMC for HIV prevention in 2007, with Ethiopia's Gambella province, the Central African Republic, and South Sudan added subsequently [9]. Implementation is 
well underway in the original 13 countries, with over 10 million VMMC performed since 2009 [10].

In 2012, the American Academy of Pediatrics produced an affirmative infant MC policy statement that highlighted the ability of $\mathrm{MC}$ to protect against multiple conditions over a lifetime. The report stated that early in pregnancy, parents should be routinely informed of the benefits and the low risk of $\mathrm{MC}$, and that third party payment for $\mathrm{MC}$ is warranted [11]. The CDC has determined that the overall adverse event rate for early infant $\mathrm{MC}$ in the US is less than $0.5 \%$, with the rate $10-20$ times higher in older boys and men than in neonates, [12] reflecting the advantages of early infant MC over adult MC [13]. Benefits exceed risks many fold, with half of uncircumcised males developing at some point at least one of the conditions against which MC offers either partial or complete lifelong protection [4]. The US has, arguably, the highest quality medical technology and expertise available in the world to those who can afford it. The most common procedure for children in US hospitals is prophylactic vaccination $(1,329,600)$ followed by $\mathrm{MC}(1,147,700)$ [14], making $\mathrm{MC}$ the most common procedure in boys.

A 2007 WHO Report estimated that approximately $30 \%$ of the world's males aged 15 years or older were circumcised [15]. In 2011, an estimate by an independent researcher found global MC prevalence to be $37-40 \%$ [16]. After examination of these previous estimates, we considered them to be out of date, since no data were provided for many countries, neither estimate was published in a peer-reviewed journal, and numerous new surveys have appeared since then. We therefore considered it timely to conduct a much more thorough evaluation aimed at determining the latest $\mathrm{MC}$ prevalence figures for every country in the world, especially in view of recent policy trends supporting the scale-up of VMMC implementation.

The aim of the present study was to determine, as realistically as possible, (i) current country-by-country and (ii) global prevalence of MC.

\section{Methods}

\section{Literature searches}

The method we used to determine MC prevalence in each country is shown in Fig. 1. Prevalence of recorded MC was extracted from published articles retrieved through a PubMed search on 2 June 2014 (updated 1 Oct 2015) using the search terms "male circumcision" combined with either "rate" (480 hits), "prevalence" (1497 hits) or "incidence" (1548 hits). Articles published prior to 2000 were excluded since MC practices can change over time. Preference was given to the most recent nationally-representative surveys, where available, to arrive at the most valid $\mathrm{MC}$ prevalence estimate in a country. Available subnational data, such as in Brazil, are shown as well to illustrate variation in MC prevalence between different parts of a country. Altogether, 143 publications contained relevant MC data for inclusion, of which 78 were dated from 2010 onwards.

Since MC takes place at different ages according to varying cultural practices, the sources we included contained data for mature males rather than boys, with the exception of Canada where only data for infants are available. Survey data for mature males therefore

Search PubMed and Internet

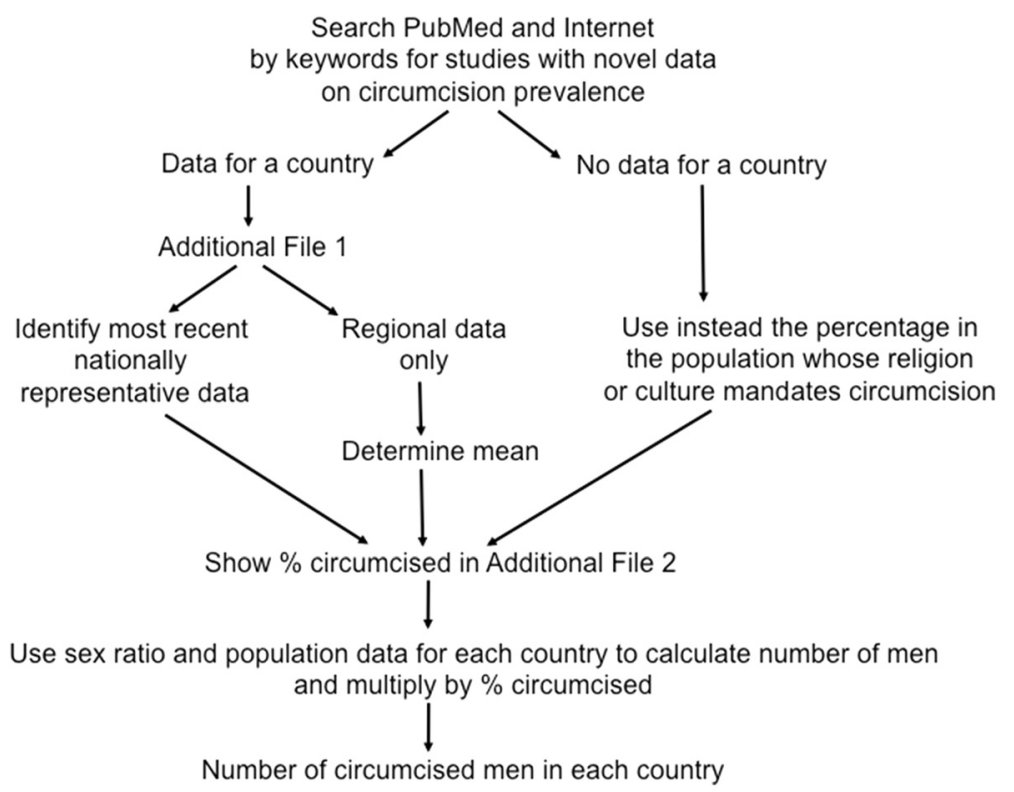

Fig. 1 Flow chart of strategy used to obtain an estimate of circumcision prevalence in each country 
included MCs performed for cultural reasons in childhood and adolescence. We obtained data on MC prevalence both in countries in which it is practiced for religious, cultural, and/or health reasons and in countries where personal preference of the male or his parents predominates. Most of the latter are developed Anglophone countries, such as the US, Canada, Australia, and New Zealand.

We performed Internet searches for documents produced by authoritative bodies, including Demographic and Health Surveys (DHS), AIDS Indicator Surveys (AIS), and Behavioural Surveillance Surveys (BSS) in specific countries. Data on MC prevalence were compiled in Table 1 along with pertinent information such as whether the survey was nation-wide or involved a particular locality, the denominator or " $n$ " value on which the estimate was based, and the age range of the males surveyed. Where possible, preference was given to nation-wide data rather than local estimates. When more than one study provided what appeared to be a representative MC prevalence for a particular country, preference was given to larger, most recent surveys. If there was more than one suitable data source, a weighted average was used to estimate percentage of circumcised men in the country.

\section{Countries lacking data}

For many countries, no data were available for MC prevalence. We therefore prepared estimates of MC performed for religious or cultural reasons or medical treatment. MC is virtually universal in Jewish and Muslim populations [1, 15, 17]. Data for Muslim population sizes in various countries usually are known more precisely than $\mathrm{MC}$ prevalence in those countries [18, 19]. Data for the percentage of Jews by country were obtained from the Jewish Virtual Library [20]. Data for the percentage of Muslims by country were obtained from Pew Research Center reports [18, 19]. For each country that lacked survey data for the percentage of circumcised males, the prevalence of MC was estimated from the sum of the numbers of Jewish and Muslim males. We assumed that $99.9 \%$ of these, but none of non-Jewish and non-Muslim males, were circumcised. This compares with an assumption of $100 \%$ used in the 2007 WHO estimates [15].

Circumcision of males as part of "coming of age" rituals is common in a substantial proportion of countries in eastern and southern Africa [17, 21], thus contributing to the high proportion of circumcised males found by self-report in DHS and AIS in those countries. Similarly, in many Pacific Island countries, $\mathrm{MC}$ is a cultural practice that forms part of traditional "coming of age" ceremonies of the indigenous Polynesian population [21-24]. Since the statistics on MC in Polynesian countries are not well-documented, estimates of $\mathrm{MC}$ prevalence in these countries were based on the proportion of people in each country who are indigenous, as ascertained by Internet searches by the name of the country and population category. In countries lacking survey data, but with high adherence to cultural customs concerning $\mathrm{MC}$, the proportion of circumcised indigenous males was assumed to approximate $95 \%$. Since the total population of all Pacific Island nations represents about $0.1 \%$ of the world's population [25], data for Pacific Island countries made little contribution to our estimate of global MC prevalence.

Since MC is performed worldwide to treat adverse medical conditions such as phimosis, paraphimosis, balanoposthitis, and penile cancer [4,26-28], no country is likely to have a MC prevalence of zero. We therefore set the lowest estimate for any country at $0.1 \%$, which we regard as conservative. In Denmark, for example, where nonmedical circumcision is rare, a large survey found $4.5 \%$ of Lutheran and non-religious men were circumcised [29]. Most of these MCs took place after infancy and, given historical opposition to MC in Denmark, were probably for treatment of an adverse medical condition caused by the presence of the foreskin [29]. In Australia, where MC has been common in infancy for many years, of the $11.5 \%$ of circumcised men in one study who had been circumcised after infancy, the main reasons were phimosis $(43 \%)$ and parental wishes (40\%) [30].

\section{Estimation of global prevalence}

In order to estimate the global prevalence of circumcision, we started with known figures for number of males in each country using two different authorities due to limitations in various databanks. We used CIA data for the total population of each country in the world [25] and data for sex ratio [31]. The total male population for each country was then determined using the formula $a /(a+1) x b$, where "a" is the ratio of males-to-females in a given country [31] and "b" is the total population of that country [25]. For six very small countries with populations between 48 and 2210 (Christmas Island, Niue, Norfolk Island, Pitcairn Island, Svalbard, and Tokelauno) no data were available, so the average sex ratio for the entire world of 1.014 males per female [31] was used instead in our calculations. The second source, UN data for males aged 15-64 years [32], provides the age range used by most surveys that estimate $\mathrm{MC}$ prevalence. This database, however, lacks information for 45 countries and territories, many of which are small. Dividing the number of circumcised males by the total number of males in a country gave figures for the fraction of circumcised males in each country.

We then summed the number of males in each country to obtain the total number of males in the world. 
Table 1 Percentage of circumcised males in each of the 237 countries and territories in the world ${ }^{a}$

\begin{tabular}{|c|c|c|c|c|c|}
\hline Country/territory & MC \% & Country/territory & MC \% & Country/territory & MC \% \\
\hline Afghanistan & 99.8 & Ghana & 91.6 & Oman & 87.7 \\
\hline Albania & 47.7 & Gibraltar & 6 & Pakistan & 96.4 \\
\hline Algeria & 97.9 & Greece & 4.7 & Palau & 95 \\
\hline American Samoa & 95 & Greenland & 0.1 & Panama & 0.95 \\
\hline Andorra & 1.1 & Grenada & 0.3 & Papua New Guinea & 10.1 \\
\hline Angola & 57.5 & Guam & 95 & Paraguay & 0.11 \\
\hline Anguilla & 0.3 & Guatemala & 0.11 & Peru & 3.7 \\
\hline Antigua \& Barbuda & 0.6 & Guernsey & 0.1 & Philippines & 91.7 \\
\hline Argentina & 2.9 & Guinea & 84.2 & Pitcairn Islands & 0 \\
\hline Armenia & 0.1 & Guinea-Bissau & 93.3 & Poland & 0.11 \\
\hline Aruba & 0.46 & Guyana & 12 & Portugal & 0.61 \\
\hline Australia & 26.6 & Haiti & 6.2 & Puerto Rico & 0.14 \\
\hline Austria & 5.8 & Holy See (Vatican) & 0.1 & Qatar & 77.5 \\
\hline Azerbaijan & 98.5 & Honduras & 0.1 & Romania & 0.34 \\
\hline Bahamas, The & 0.2 & Hong Kong & 28 & Russia & 11.8 \\
\hline Bahrain & 81.2 & Hungary & 0.78 & Rwanda & 13.3 \\
\hline Bangladesh & 93.2 & Iceland & 0.1 & Saint Barthelemy & 0.1 \\
\hline Barbados & 0.9 & India & 13.5 & Saint Helena, Ascens & 0.1 \\
\hline Belarus & 0.32 & Indonesia & 92.5 & Saint Kitts \& Nevis & 0.3 \\
\hline Belgium & 22.6 & Iran & 99.7 & Saint Lucia & 0.1 \\
\hline Belize & 0.1 & Iraq & 98.9 & Saint Martin \& Tristan & 0.1 \\
\hline Benin & 92.9 & Ireland & 0.93 & Saint Pierre \& Miquel & 0.2 \\
\hline Bermuda & 0.8 & Isle of Man & 0.2 & Saint Vincent \& Grena & 1.7 \\
\hline Bhutan & 1.0 & Israel & 91.7 & Samoa & 95 \\
\hline Bolivia & 0.11 & Italy & 2.6 & San Marino & 0.1 \\
\hline Bosnia \& Herzegovina & 41.6 & Jamaica & 14 & Sao Tome \& Principe & 0.1 \\
\hline Botswana & 15.1 & Japan & 9 & Saudi Arabia & 97.1 \\
\hline Brazil & 1.3 & Jersey & 0.1 & Senegal & 93.5 \\
\hline British Virgin Islands & 1.2 & Jordan & 98.8 & Serbia & 3.71 \\
\hline Brunei & 51.9 & Kazakhstan & 56.4 & Seychelles & 1.1 \\
\hline Bulgaria & 13.4 & Kenya & 91.2 & Sierra Leone & 96.1 \\
\hline Burkin Faso & 88.3 & Kiribati & 0.1 & Singapore & 14.9 \\
\hline Burma & 3.5 & Korea, North & 0.1 & Sint Maarten & 0.06 \\
\hline Burundi & 61.7 & Korea, South & 77.0 & Slovakia & 0.15 \\
\hline Cabo Verde & 0.1 & Kosovo Islands & 91.7 & Slovenia & 8.5 \\
\hline Cambodia & 3.5 & Kuwait & 86.4 & Solomon Islands & 95 \\
\hline Cameroon & 94.0 & Kyrgyzstan & 91.9 & Somalia & 93.5 \\
\hline Canada & 31.9 & Laos & 0.1 & South Africa & 44.7 \\
\hline Cayman Islands & 0.2 & Latvia & 0.38 & South Sudan & 23.6 \\
\hline Central African Republic & 63.0 & Lebanon & 59.7 & Spain & 6.6 \\
\hline Chad & 73.5 & Lesotho & 52 & Sri Lanka & 8.5 \\
\hline Chile & 0.21 & Liberia & 97.7 & Sudan & 39.4 \\
\hline China & 14.0 & Libya & 96.6 & Suriname & 15.9 \\
\hline Christmas Island & 0.1 & Liechtenstein & 4.8 & Svalbard & 0.1 \\
\hline
\end{tabular}


Table 1 Percentage of circumcised males in each of the 237 countries and territories in the world ${ }^{\text {a }}$ (Continued)

\begin{tabular}{|c|c|c|c|c|c|}
\hline Cocos (Keeling) & 95 & Lithuania & 0.2 & Swaziland & 8.2 \\
\hline Columbia & 4.2 & Luxembourg & 2.4 & Sweden & 5.1 \\
\hline Comoros & 99.4 & Macau & 0.1 & Switzerland & 5.9 \\
\hline Congo, Democrat Repub & 97.2 & Macedonia & 33.9 & Syria & 92.8 \\
\hline Congo, Republic & 70 & Madagascar & 94.7 & Taiwan & 8.3 \\
\hline Cook Islands & 95 & Malawi & 21.6 & Tajikistan & 99 \\
\hline Costa Rica & 0.15 & Malaysia & 61.4 & Tanzania & 72 \\
\hline Cote d'Ivoire & 96.7 & Maldives & 98.4 & Thailand & 23.4 \\
\hline Croatia & 1.3 & Mali & 86 & Timor-Leste & 6.4 \\
\hline Cuba & 0.11 & Malta & 0.3 & Togo & 95.2 \\
\hline Curacao & 0.07 & Marshall Islands & 0.1 & Tokelau & 95 \\
\hline Cyprus & 22.7 & Mauritania & 99.2 & Tonga & 95 \\
\hline Czech Republic & 0.14 & Mauritius & 16.6 & Trinidad \& Tobago & 5.8 \\
\hline Denmark & 5.3 & Mexico & 15.4 & Tunisia & 99.8 \\
\hline Djibouti & 96.5 & Micronesia, Fed States & 0.1 & Turkey & 98.6 \\
\hline Dominica & 0.2 & Moldova & 0.5 & Turkmenistan & 93.4 \\
\hline Dominican Republic & 13.7 & Monaco & 0.5 & Turks \& Caicos Is & 0.1 \\
\hline Ecuador & 0.11 & Mongolia & 4.4 & Tuvalu & 95 \\
\hline Egypt & 94.7 & Montenegro & 18.5 & Uganda & 26.7 \\
\hline El Salvador & 0.11 & Montserrat & 0.1 & Ukraine & 2.3 \\
\hline Equatorial Guinea & 87 & Morocco & 99.9 & United Arab Emirates & 76 \\
\hline Eritrea & 97.2 & Mozambique & 47.4 & United Kingdom & 20.7 \\
\hline Estonia & 0.25 & Namibia & 25.5 & United States & 71.2 \\
\hline Ethiopia & 92.2 & Nauru & 95 & Uruguay & 0.62 \\
\hline Falkland Islands & 0.1 & Nepal & 4.2 & Uzbekistan & 96.5 \\
\hline Faroe Islands & 0.1 & Netherlands & 5.7 & Vanuatu & 95 \\
\hline Fiji & 55 & New Caledonia & 50 & Venezuela & 0.33 \\
\hline Finland & 0.82 & New Zealand & 33.0 & Vietnam & 0.2 \\
\hline France & 14 & Nicaragua & 0.1 & Virgin Islands & 0.55 \\
\hline French Polynesia & 78 & Niger & 95.5 & Wallis \& Futuna & 0.1 \\
\hline Gabon & 99.2 & Nigeria & 98.9 & West Bank & 99.9 \\
\hline Gambia, The & 94.5 & Nive & 95 & Western Sahara & 99.6 \\
\hline Gaza Strip & 99.9 & Norfolk Island & 0.1 & Yemen & 99.0 \\
\hline Georgia & 10.6 & Northern Mariana Is & 90 & Zambia & 12.8 \\
\hline Germany & 10.9 & Norway & 3.0 & Zimbabwe & 9.2 \\
\hline
\end{tabular}

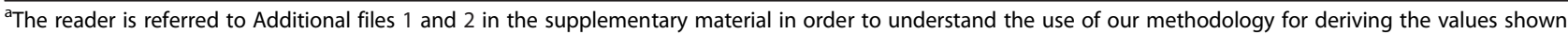
in this Table

Following this, we summed the number of circumcised males in each country to obtain a total number of circumcised males globally. Dividing the latter by the former yielded an estimate of the percentage of males globally who are circumcised. Calculation of $95 \% \mathrm{CI}$ used the equation $\sigma \pm 1.96 \div$ square root of $n$, where $\mathrm{x}$ is the mean, $\sigma$ is the standard deviation, $\mathrm{n}$ is the sample size, and the confidence coefficient is 1.96, and Excel was used to calculate the margin of error, as well as the upper and lower bound.

\section{Results}

Data obtained from surveys

Additional file 1 lists alphabetically those countries for which surveys of MC prevalence were available [26, 27, 29, 33-163] and provides reported country estimates, 
together with size of the survey, age range of males, national or regional survey scope, urban or rural and other demographic information, and the relevant citation.

\section{Estimates for all countries}

The estimated percentage of circumcised males for each country or territory appears in Additional file 2, column 4. Nationally representative survey data in this file had the benefit of involving large numbers, thus increasing the precision of the estimates. However, self-report tends to introduce uncertainty because manhood initiation ceremonies in some traditional settings of sub-Saharan Africa may or may not include complete MC [164]. Since most of the values obtained were for males aged 15 years of age and over, they reflected MCs that had been performed in infancy or by late adolescence, depending on country and culture. Purported MC estimates in infancy may be unreliable because they are based on hospital discharge data and many boys are circumcised after discharge of the mother and her baby post-partum, whereas survey data in mature males appear to be more accurate [4]. In the last column of Additional file 2, "Survey" indicates that the value shown was obtained from survey data. This file also shows the percentage of Muslims in each country (column 2) and the percentage of Jews (column 3) [33]. In instances in which cultural traditions in the form of "coming of age" rituals were used as a basis for the estimate, this is indicated as "Culture" in the last column of Additional file 2. "Culture" was also used to indicate a country in which culture does not traditionally support MC.

Additional file 2, column 6, shows the total number of circumcised males in each of the 237 countries and territories, calculated from CIA databases as described in the Methods section. For simplicity, raw values generated by our computations are shown. These are overly precise and should not be taken literally as they are merely working numbers suitable for use in further calculations. While $95 \%$ CI would help show the degree of accuracy of the estimates, these were not available for most countries. The $95 \% \mathrm{CI}$ for estimated prevalence of $\mathrm{MC}$ in the USA was $\pm 2.5 \%$ of the mean [132]. It is likely that $95 \%$ $\mathrm{CI}$ for other countries may be wider than these.

Since CIA data does not give population figures by age group, we used the UN database of number of males aged 15-64 [32] to determine MC prevalence for a limited number of countries (Additional file 3).

Table 1 summarizes the percentage of MC prevalence determined for each country and territory in the world.

\section{Estimation of global prevalence}

We then summed the total number for each country, starting first with figures obtained using the CIA database to calculate total males. This yielded an overly precise working figure of 1,412,252,836 circumcised males among the total number of 3,654,384,123 males in the world, constituting a working value for the purposes of the next calculation. Simple division of the former by the latter figure estimated global $\mathrm{MC}$ prevalence at approximately $38.65 \%$ (95 \% CI: 33.7, 44.4). Prevalence estimates were based on religion for 136 countries (57.4\%), survey data for 73 countries (30.8\%), and culture for 20 countries $(8.4 \%)$. In only seven countries $(2.9 \%)$ was no information available. In countries with survey data on MC prevalence, the total number of males was $2,694,086,787$, i.e., $73.7 \%$ of the total global male population. The percentage of circumcised males in these countries was $33.2 \%$ overall. In 63 countries (26.6\%), adult MC prevalence exceeded $90 \%$. MC prevalence was greater than the global average of $36.7-$ $38.7 \%$ in 95 countries (40.1\%) and lower in 142 (59.9\%) countries.

Given that $23.2 \%$ (1.6 billion) of the total population in the world is Muslim [18] and $0.18 \%$ is Jewish [20], the proportion of males circumcised for religious reasons globally would be approximately $62.1 \%$. The rest would have been circumcised for reasons such as individual and family preference, which could include, for example, Christian faith, depending on Biblical interpretation by individuals, medical indications, cultural reasons such as "coming of age" ceremonies, or as part of HIV prevention programs in sub-Saharan African countries experiencing epidemics of heterosexual HIV transmission.

Based on UN data for number of males aged 15-64 as the denominator in our calculation of MC prevalence (Additional file 3), we obtained a figure of $36.7 \%$ (95\% CI: 31.4, 42.0).

\section{Discussion}

The true global MC prevalence is not known precisely and can only be estimated. Nevertheless, some estimates are more reliable than others. Global MC prevalence was asserted to be $20 \%$ by Wallerstein in 1985 [165], but no sources or methodology were presented. Similarly, Williams \& Kapila [166] and Hutcheson [167] estimated a prevalence of one in six, although neither article provided a basis for the estimate.

The earliest attempt to obtain a somewhat systematic estimate concluded that $23 \%$ of males globally were circumcised [168]. That estimate, based on data through 1994, had some serious deficiencies, not least of which was the assumption, which was acknowledged as a limitation, that only Jews, Muslims, North Americans, and "Tribal Religionists" in Africa were circumcised. There was also poor consideration of populations falling into multiple groups; for example, North American Muslims appeared to have been counted twice. 
The WHO published online a better attempt to estimate global prevalence in 2007 [15]. This analysis utilized global numbers of Muslims and Jews as a base, and then added MC prevalence of the non-Muslim, nonJewish populations of 17 countries. From the resulting total, global prevalence was calculated as $30 \%$. A weakness of the approach was that MC prevalence data were likely gathered from a population sample that included Muslims and Jews, resulting in a probable overestimate when applied to the smaller non-Muslim, non-Jewish population. A second weakness was the relatively small number of countries for which non-religious MCs were considered. The increasing proportion of Muslims in the world population over time [19], as well as on-going VMMC programs in sub-Saharan Africa, might account in part for our higher estimate of 37-39\% for global MC prevalence compared to the $30 \%$ reported in 2007 by the WHO based on an incomplete set of countries globally [7]. Additionally, since 2007 there has been a substantial increase in the availability of survey data, such as those compiled by DHS, AIS, and other reputable bodies, as well as publications in peer-reviewed journals, resulting in a stronger information base. A $34 \%$ increase in infant MC in Germany between 2008 and 2011 could have been from a rise in the Muslim population in this traditionally non-circumcising country or perhaps other factors [169]. A disproportionate rise in Muslim immigrants as a proportion of the total population of other countries would contribute to increases in $\mathrm{MC}$ prevalence in each.

While the present study involved the most thorough analysis yet conducted, several limitations should be noted. All studies to date have suffered from the general difficulty of estimating MC prevalence in the absence of national surveys for every country. This may, however, be improving because DHS and AIS have increased their inclusion of questions on self-reported MC status. Survey data are based on the subpopulation of the total population that participated in the survey. Uncertainty could be of the order of 5-10\%. The $95 \%$ CI for US estimates by the CDC were $\pm 2.5 \%$ of the mean, indicative of a high degree of precision in that study [132]. Large nationally representative surveys were more likely to provide the most accurate estimates of MC prevalence, whereas small surveys in sub-regions of a country have the potential to generate MC prevalence data that deviate from the actual national figure. As an example, a more recent, larger national survey in Brazil found overall $\mathrm{MC}$ prevalence to be $1.3 \%$ [48], noting higher figures for cities in the south compared with rural areas in the north of this country. This demonstrated that MC prevalence figures from older surveys confined to Sao Paulo [50-52] and Rio de Janeiro [49] had yielded figures higher than the national average.
As well as significant regional variation in MC prevalence in some surveys, there was a higher prevalence noted among individuals and families with higher education and income.

Our estimates for MC prevalence in many smaller countries and territories tended to be less precise. Since those countries were small, however, the estimates for them made little contribution to our estimate of global $\mathrm{MC}$ prevalence. We chose, however, not to group these separately because we expected some readers would be interested in seeing estimates for these individual countries or territories.

Because CIA data only allowed us to estimate the total number of males in each country, whereas most surveys we used gave estimates of MC prevalence for males aged $\geq 15$ years, our estimates for the total number of circumcised males when using CIA data for total males applied $\mathrm{MC}$ estimates to the total number of males regardless of age. Using this approach, we assumed, however, that if MC was performed it would have taken place in most males by 15 years of age. We nevertheless recognize that $\mathrm{MC}$ incidence may be rising or falling in some countries. This represents an unavoidable potential limitation to estimates based on CIA data for number of males in each country.

We overcame this limitation by using UN estimates of males aged 15-64 in each country. But the drawback of the UN database was that it did not include 45 countries. Nevertheless, those countries that were included likely led us to generate more accurate MC estimates for those than when using CIA figures for total males.

As a consequence of the absence of MC survey data available for many countries, it was necessary to estimate MC prevalence in some countries on the basis of the prevalence of ethnic/religious groups known to perform it, most notably Muslims [18, 19] and Jews [20]. Estimating $\mathrm{MC}$ prevalence based on the prevalence of certain religions in some countries is not completely accurate because (i) uncircumcised Muslims and Jews do exist, so the proportion of circumcised males in these groups is less than $100 \%$, which is why we used a figure of $99.9 \%$, and (ii) a percentage (possibly 5-10\% in developed countries) of males are circumcised for medical reasons such as phimosis, paraphimosis, balanitis, or conservative treatment of early stage penile cancer [28]. In this regard, our use of a minimum of $0.1 \%$ for $\mathrm{MC}$ prevalence in a country for which no survey data were available is likely to be an underestimate.

In relation to religion, examination of countries that had both survey data on proportion of Muslims who were circumcised and data on the Muslim population proportion showed a close match: Comoros (99.4\% vs. $98.2 \%$, respectively), Gambia (90.0-99.0 \% vs. $95.3 \%)$, Guinea (96.0 \% vs. $84.2 \%)$, Indonesia (92.5 \% vs. $88.1 \%$ ), 
Mali (86.0 \% vs. $92.4 \%)$, Mauritania (77.0 \% vs. $99.2 \%)$, Niger (92.0-99.0 \% vs. $98.3 \%$ ), Sierra Leone (96.1 \% vs. $71.5 \%$ ), and Somalia (93.0-94.0 \% vs. 98.6 \%). The one exception was Albania, where survey data suggested $47.7 \%$ of males were circumcised but $77.9 \%$ of the population was Muslim [33]. An AIDS Indicator Survey of Uganda determined the prevalence of $\mathrm{MC}$ in Muslim men and found $99.6 \%$ were circumcised [148]. Data for other countries show, with few exceptions, a MC prevalence of 95-100\% for Muslims. In Albania, and possibly other countries, it is possible that a proportion of Muslims remained uncircumcised, that $\mathrm{MC}$ had not taken place by the age of 15 years, or there might have been reporting bias. Survey data for the UK found $98.7 \%$ of Jewish men were circumcised [151]. From available data, it seems that the bigger the Muslim or Jewish population in a country, the more closely the actual $\mathrm{MC}$ prevalence likely matches the percentage of Muslims or Jews. In contrast, in countries in which Muslim people are minorities, the proportion of Muslim males who are circumcised was 71-85\%. Perhaps societal or access factors in such countries may be influencing the decision by Muslim or Jewish parents to have their boy circumcised.

Cultural considerations are of interest, especially in the world's most populous country, China, where circumcision is not generally part of the culture [170]. Prevalence in China varies by subregion and there is a growing Muslim population in China's western provinces. Awareness of the health benefits may be rising, as judged by publications and research by Chinese investigators, as well as the development in China of MC devices such as the Shang Ring [171].

In sub-Saharan Africa, early recognition of the strong correlation between low MC prevalence and higher HIV prevalence prompted epidemiological studies to determine whether the two were linked. Confirmation of the causal link in several randomized controlled trials led to the promotion of MC for HIV prevention, with over 10 million having already undergone the procedure since 2009 [10]. Figure 2 uses the current data and the most recent country-specific HIV figures [9] to demonstrate this relationship in Africa.

Predicting MC prevalence based upon religion or culture is an approximation at best. Comparing countries for which both predicted and reported $\mathrm{MC}$ rates are available showed that reported MC prevalence generally exceeded religion-based predictions for these particular countries (Additional file 2). This may suggest that actual MC prevalence is greater than the value we estimated based on religion or culture in some countries lacking $\mathrm{MC}$ survey data. However, large surveys base MC prevalence on selfreports and even with the use of drawings or photographs to assist men in accurate self-reporting, some men who are not circumcised report that they are, while some who are circumcised report that they are not [94, 164, 172]. For

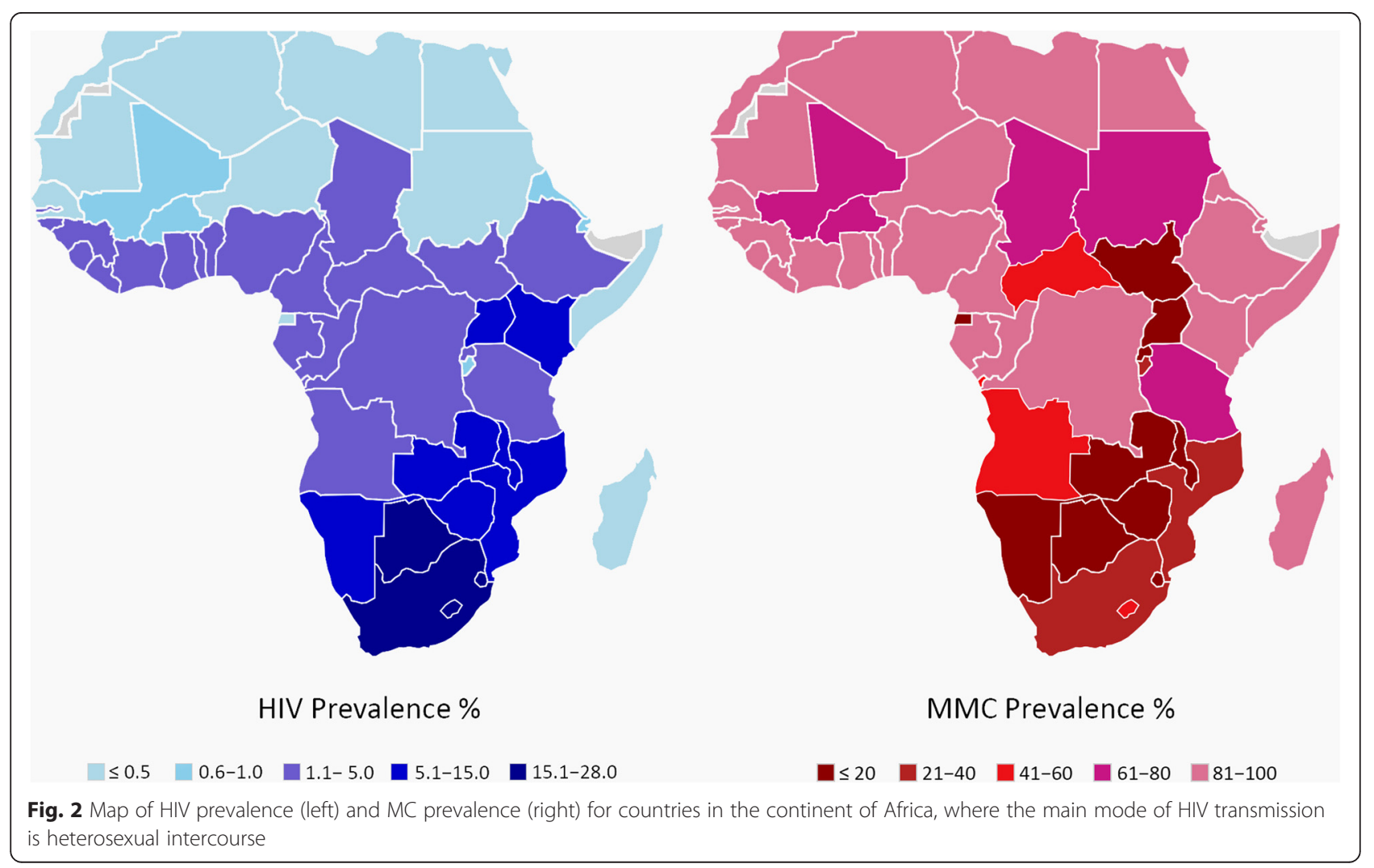


$30.8 \%$ of countries, MC prevalence was based on survey data rather than religion. The total number of men in these countries ( 2.7 billion) comprised $73.7 \%$ of the global population of males. The proportion of males in surveyed countries who were circumcised was $33.2 \%$. Considering that there were 73 countries with survey data (30.8\%), but $136(57.4 \%)$ with data based on religion and 20 (8.4\%) based on culture, our estimate for global MC prevalence of 36.7-38.7 \% would appear reasonable, particularly in light of possible underestimation of circumcisions in nonsurvey countries performed for medical reasons or personal preference.

\section{Conclusions}

As accurately as might reasonably be expected, the present study has determined estimates for the prevalence of $\mathrm{MC}$ in every country in the world. Altogether, our findings suggest that MC prevalence globally is approximately $37.7 \%$, although the real percentage could be slightly higher or lower than this. Given the known benefits and low risks of MC [4] and recent affirmative recommendations in the interests of public health and disease prevention by the American Academy of Pediatrics, the CDC, the WHO and UNAIDS, as well as the large-scale roll out of VMMC by multilateral donors and agencies, the present findings on current prevalence of MC across geographies and cultures may help guide policy development and resource allocation in all countries.

\section{Additional files}

Additional file 1: This spreadsheet provides data from published surveys on MC prevalence in all countries for which such studies have been conducted. (XLSX $45 \mathrm{~kb})$

Additional file 2: This spreadsheet shows data for number of males using $\mathrm{CIA}$ data and estimates of number of circumcised males in all 237 countries and territories in the world, as well as basis for the estimate and MC percentage for each. (XLSX $32 \mathrm{~kb}$ )

Additional file 3: This spreadsheet shows data for number of males using UN data for all but $\mathbf{4 5}$ countries and territories in the world and estimates of number of circumcised males in all but these 45 , as well as basis for the estimate and MC percentage for each. (XLSX $29 \mathrm{~kb}$ )

\section{Competing interests}

The authors declare they have no competing interests.

\section{Authors' contributions}

BM set up the study design and was responsible for the conceptualization of the study. BM led the drafting. BM, RW and EH were responsible for data acquisition analyses. JB compiled Fig. 2. BM wrote the initial draft. All authors contributed to the interpretation and final manuscript drafting and approved the final version of the manuscript.

\section{Author details}

${ }^{1}$ School of Medical Sciences and Bosch Institute, University of Sydney, Sydney, NSW 2006, Australia. ${ }^{2}$ Department of African-American Studies, Northeastern University, Boston, MA 02115, USA. ${ }^{3}$ College of Science, Northeastern University, Boston, MA 02115, USA. ${ }^{4}$ Department of Pathology,
School of Medicine, Johns Hopkins University, Baltimore, MD 21287, USA. ${ }^{5}$ Division of Infectious Diseases and Program in Global Health, David Geffen School of Medicine, University of California Los Angeles (UCLA), Los Angeles, CA 90095, USA. ${ }^{6} \mathrm{Jhpiego}$, an affiliate of Johns Hopkins University, Washington, DC 20009, USA. ${ }^{7}$ Department of Global Health, Academic Medical Centre and Amsterdam Institute for Global Health and Development, University of Amsterdam, Amsterdam 1105 AZ, The Netherlands. ${ }^{8}$ Department of Infectious Disease Epidemiology, Faculty of Epidemiology and Population Health, London School of Hygiene and Tropical Medicine, London WC1E 7HT, UK.

Received: 27 February 2015 Accepted: 12 February 2016

Published online: 01 March 2016

\section{References}

1. Cox G, Morris BJ. Why circumcision: From pre-history to the twenty-first century. In: Bolnick DA, Koyle MA, Yosha A, editors. Surgical Guide to Circumcision. London: Springer; 2012. p. 243-59.

2. Morris BJ, Cox G. Current medical evidence supports male circumcision. In: Bolnick DA, Koyle MA, Yosha A, editors. Surgical Guide to Circumcision. London: Springer; 2012. p. 201-13.

3. Morris BJ, Wiswell TE. Circumcision and lifetime risk of urinary tract infections: A systematic review and meta-analysis. J Urol. 2013;189:2118-24.

4. Morris BJ, Bailis SA, Wiswell TE. Circumcision rates in the United States: Rising or falling? What effect might the new affirmative pediatric policy statement have? Mayo Clin Proc. 2014;89(5):677-86.

5. Morris BJ, Castellsague X. The role of circumcision in preventing STIs. In: Gross GE, Tyring SK, editors. Sexually Transmitted Infections and Sexually Transmitted Diseases. Berlin and Heidelberg: Springer; 2011. p. 715-39.

6. Siegfried N, Muller M, Deeks JJ, Volmink J. Male circumcision for prevention of heterosexual acquisition of HIV in men. Cochrane Database Syst Rev 2009;Issue 2:CD003362. http://www.ncbi.n/m.nih.gov/pubmed/ ?term=siegfried $+n+2009+$ male+circumcision+cochrane.

7. World Health Organization and UNAIDS. (2007) New data on male circumcision and HIV prevention: policy and programme implications. 2007. http://who.int/ hiv/mediacentre/MCrecommendations_en.pdf. Accessed 15 Sep 2015.

8. UNAIDS. Safe, Voluntary, Informed Male Circumcision and Comprehensive HIV Prevention Programming: Guidance for decision-makers on human rights, ethical \& legal considerations. 2008:http://data.unaids.org/pub/ Report/2008/JC1552_Circumcision_en.pdf. Accessed 16 Sep 2015.

9. UNAIDS report on the global AIDS epidemic 2013. 2013. http://www.unaids. org/en/media/unaids/contentassets/documents/epidemiology/2013/gr2013/ UNAIDS_Global_Report_2013_en.pdf. Accessed 2 Oct 2014.

10. UNAIDS. Fast-Tracking Combination Prevention: Towards reducing new HIV Infections to fewer than 500000 by 2020. Joint United Nations Programme on HIV/AIDS; 2015. http://www.unaids.org/sites/default/files/ media_asset/20151019_JC2766_Fast-tracking_combination_prevention. pdf 2015 (accessed 26 Feb 2016).

11. American Academy of Pediatrics. Circumcision policy statement,Task Force on Circumcision. Pediatrics. 2012;130(3):e756-85.

12. El Bcheraoui C, Zhang X, Cooper CS, et al. Rates of adverse events associated with male circumcision in US medical settings, 2001 to 2010. JAMA Pediatr. 2014;168(7):625-34.

13. Morris $B J$, Waskett $J H$, Banerjee J, et al. A 'snip' in time: what is the best age to circumcise? BMC Pediatr. 2012;12(20):1-15.

14. Yu H, Wier LM, Elixhauser A. Hospital stays for children, 2009. Hospital Cost Utilization Project (HCUP), Statistical Brief \#1 18. http://www.hcup-us.ahrq. gov/reports/statbriefs/sb1 18.jsp. Accessed 3 Mar 2014.

15. WHO and UNAIDS. Male circumcision: global trends and determinants of prevalence, safety and acceptability. (42 pp; 191 refs) World Health Organization. Geneva: World Health Organization. http://apps.who.int/iris/ bitstream/10665/43749/1/9789241596169_eng.pdf. Last accessed 17 Aug 2015.

16. Waskett JH. Global circumcision rates. Circumcision Independent reference and Commentary Service. https://web.archive.org/web/20120805153305/ http://www.circs.org/index.php/Reviews/Rates/Global. Accessed 18 Feb 2014.

17. Drain PK, Halperin DT, Hughes JP, et al. Male circumcision, religion, and infectious diseases: an ecologic analysis of 118 developing countries. BMC Infect Dis. 2006;6(172):1-10.

18. Pew Research Religion \& Public Life Project. Muslim Population by Country. http://www.pewforum.org/2011/01/27/table-muslim-population-by-country/. Accessed 12 Jun 2014. 
19. Desilver D. Pew Research Center. World's Muslim population more widespread than you might think. http://www.pewresearch.org/fact-tank/ 2013/06/07/worlds-muslim-population-more-widespread-than-you-mightthink/. Accessed 18 Feb 2014

20. Jewish Virtual Library. Vital statistics: Jewish population of the world (1882 - present). 2014. http://www.jewishvirtuallibrary.org/jsource/ Judaism/jewpop.html. Accessed 19 Oct 2015.

21. World Health Organization. Traditional male circumcision and young people: A public health perspective in the context of HIV prevention. http:// www.malecircumcision.org/programs/documents/TMC_final_web.pdf. Accessed 6 Oct 2014.

22. Afsari M, Beasley SW, Maoate K, Heckert K. Attitudes of Pacific parents to circumcision of boys. Pac Health Dialog. 2002;9:29-33.

23. Hollan DW, Wellenkamp JC. The Thread of Life: Toraja Reflections on the Life Cycle. Hawaii: The University of Hawaii Press; 1996.

24. Silverman EK. Anthropology and circumcision. Annu Rev Anthropol. 2004;33: 419-45.

25. Central Intelligence Agency. Country comparison: Population. In: The World Factbook. http://www.cia.gov/library/publications/the-world-factbook/ rankorder/2119rank.html. Accessed 16 Oct 2015.

26. Introcaso $\mathrm{CE}, \mathrm{Xu} \mathrm{F}$, Kilmarx $\mathrm{PH}$, et al. Prevalence of circumcision among men and boys aged 14 to 59 years in the United States, national health and nutrition examination surveys 2005-2010. Sex Transm Dis. 2013;40(7):521-5.

27. Hart-Cooper GD, Tao G, Stock JA, Hoover KW. Circumcision of privately insured males aged 0 to 18 years in the United States. Pediatrics. 2014;134(5):950-6.

28. Clark SJ, Kilmarx PH, Kretsinger K. Coverage of newborn and adult male circumcision varies among public and private US payers despite health benefits. Health Aff (Millwood). 2011;30:2355-61.

29. Frisch M, Lindholm M, Grønbeck M. Male circumcision and sexual function in men and women: a survey-based-cross-sectional study in Denmark. Int J Epidemiol. 2011;40:1367-81.

30. Mao LM, Templeton DJ, Crawford J, et al. Does circumcision make a difference to the sexual experience of gay men? Findings from the Health in Men (HIM) Cohort. J Sex Med. 2008:5:2557-61.

31. Central Intelligence Agency. Field listing: Sex ratio. In: The World factbook. http://www.cia.gov/library/publications/the-world-factbook/fields/2018.html. Accessed 16 Oct 2015.

32. United Nations, Department of Economic and Social Affairs, Population Division. World Population Prospects. 2015. http://esa.un.org/unpd/wpp/. Accessed 20 Oct 2015.

33. The DHS Program. Demographic and Health Surveys, Albania. 2008-09. Table 12.11. 2010. http://dhsprogram.com/pubs/pdf/FR230/FR230.pdf. Accessed 14 Mar 2014.

34. United Nations High Commissioner for Refugees \& Botswana Ministry of Health. HIV/AIDS Behavioural Surveillance Survey (BSS). Dukwi Refugee Camp, Botswana. Table 29. 2013. p. 47-9. http://www.unhcr.org/51b5d6979. html. Accessed 16 Sep 2015.

35. Williams BG, Lloyd-Smith JO, Gouws E, et al. The potential impact of male circumcision on HIV in Sub-Saharan Africa. PLoS Med. 2006;e262:1032-40.

36. Ferris JA, Richters J, Pitts MK, et al. Circumcision in Australia: further evidence on its effects on sexual health and wellbeing. Aust N Z J Publ Hlth. 2010;34:160-4.

37. Australian Government, Department of Human Services. Medicare Item Reports. http://medicarestatistics.humanservices.gov.au/statistics/mbs_item. jsp. Accessed 6 Oct 2015

38. Dahlen HG, Tracy S, Tracy M, et al. Rates of obstetric intervention and associated perinatal mortality and morbidity among low-risk women giving birth in private and public hospitals in NSW (2000-2008): a linked data population-based cohort study. BMJ Open. 2014;4(5):e004551.

39. Sabin KM, Rahman M, Hawkes $S$, et al. Sexually transmitted infections prevalence rates in slum communities of Dhaka, Bangladesh. Int J STD AIDS. 2003;14:614-21.

40. Timberg C, Halperin D. Tinderbox: How the West Sparked the AIDS Epidemic and How the World Can Finally Overcome it. New York: The Penguin Press; 2012

41. Bronselaer GA, Schober JM, Meyer-Bahlburg HF, et al. Male circumcision decreases penile sensitivity as measured in a large cohort. BJU Int. 2013;111:820-7.

42. The DHS Program. Demographic and Health Surveys, Benin 2011-2012. Table 13.13. 2013. http://dhsprogram.com/pubs/pdf/FR270/FR270.pdf. Accessed 14 Mar 2014
43. Auvert B, Buvé A, Lagarde E, et al. Male circumcision and HIV infection in four cities in sub-Saharan Africa. AIDS. 2001;15 Suppl 4:S31-40.

44. Kebaabetswe P, Lockman S, Mogwe S, et al. Male circumcision: an acceptable strategy for HIV prevention in Botswana. Sex Transm Infect. 2003;79:214-9.

45. Botswana HIV/AIDS Programmes. 2008 Botswana AIDS Impact Survey III (BAIS III - 2008). Table 210a/b. 2008. http://www.hiv.gov.bw/content/2008botswana-aids-impact-survey-iii-bais-iii-2008. Accessed 16 Sep 2015.

46. Ayiga N, Letamo G. Impact of male circumcision on HIV risk compensation through the impediment of condom use in Botswana. Afr Health Sci. 2011;11:550-9.

47. Andersson N, Cockcroft A. Male circumcision, attitudes to HIV prevention and HIV status: a cross-sectional study in Botswana, Namibia and Swaziland. AIDS Care. 2012;24:301-9.

48. Korkes F, Silva 2nd JL, Pompeo AC. Circumcisions for medical reasons in the Brazilian public health system: epidemiology and trends. Einstein (Sao Paulo). 2012;10:342-6.

49. Périssé $A R$, Schechter $M$, Blattner W. Association between male circumcision and prevalent HIV infections in Rio de Janeiro, Brazil. J Acquir Immune Defic Syndr. 2009;50:435-7.

50. Castellsagué X, Bosch FX, Munoz N, et al. Male circumcision, penile human papillomavirus infection, and cervical cancer in female partners. N Engl Med. 2002:346:1105-12.

51. Castellsagué X, Peeling RW, Franceschi S, et al. Chlamydia trachomatis infection in female partners of circumcised and uncircumcised adult men. Am J Epidemiol. 2005;162:907-16.

52. Albero $G$, Castellsagué $X$, Lin HY, et al. Male circumcision and the incidence and clearance of genital human papillomavirus (HPV) infection in men: the HPV Infection in men (HIM) cohort study. BMC Infect Dis. 2014;14(75):1-12.

53. The DHS Program. Demographic and Health Surveys, Burkina Faso 2010. Table 14.13. 2012. http://dhsprogram.com/pubs/pdf/FR256/FR256. Accessed 14 Mar 2014.

54. The DHS Surveys. Demographic and Health Surveys, Burundi. Table 14.13. 2012. http://dhsprogram.com/pubs/pdf/FR253/FR253.pdf. Accessed 14 Mar 2014.

55. United Nations High Commissioner for Refugees. HIV and AIDS Behavioural Surveillance Survey, Tanzania Refugee Camps and Surrounding Host Communities http://www.unhcr.org/4de504d39.html. Accessed 18 Oct 2015.

56. United Nations High Commissioner for Refugees. HIV and AIDS Behavioural Surveillance Survey, Marratane Refugee Camp, Mozambique, section 6.4 2005. http://www.unhcr.org/452f5d0b2.html. Accessed 4 Jul 2014

57. The DHS Program. Demographic and Health Surveys, Cameroon, 2011 Table 14.13. 2012. http://dhsprogram.com/pubs/pdf/FR260/FR260.pdf. Accessed 14 Mar 2014.

58. To T, Agha M, Dick PT, Feldman W. Cohort study on circumcision of newborn boys and subsequent risk of urinary tract infection. Lancet. 1998; 352:1813-6.

59. Public Health Agency of Canada. What Mothers Say. Data Tables to The Maternity Experiences Survey (MES) 2006-2007. Table 38. 2011. p.267. http:// www.phac-aspc.gc.ca/rhs-ssg/pdf/tab-eng.pdf. Accessed 2 Apr 2015

60. Peltzer K, Niang Cl, Muula AS, et al. Male circumcision, gender and HIV prevention in sub-Saharan Africa: a (social science) research agenda. J Soc Asp HIV/AIDS (SAHARA J). 2007:4:658-67.

61. Ben $K L, X u J C$, Lu L, et al. [Promoting male circumcision in China for preventing HIV infection and improving reproductive health] (Article in Chinese). Zhonghua Nan Ke Xue. 2008;14:291-7.

62. Ruan $Y$, Qian $H Z$, Li D, et al. Willingness to be circumcised for preventing HIV among Chinese men who have sex with men. AIDS Patient Care STDS. 2009;23:315-21.

63. Sullivan SG, Ma W, Duan S, et al. Attitudes towards circumcision among Chinese men. J Acquir Immune Defic Syndr. 2009:50:238-40.

64. Yang C, Liu X, Wei GH. Foreskin development in 10421 Chinese boys aged 0-18 years. World J Pediatr. 2009;5:312-5.

65. Lau JT, Yan H, Lin C, et al. How willing are men who have sex with men in China to be circumcised for the sake of protecting his female sex partner? J Sex Med. 2012;9:1904-12.

66. Wan S, Wang Y, Gu S. Epidemiology of male genital abnormalities: a population study. Pediatrics. 2014;133:e624-7.

67. Zeng $Y$, Zhang L, Li T, et al. Risk factors for HIV/syphilis infection and male circumcision practices and preferences among men who have sex with men in China. Biomed Res Int. 2014;498987:1-9. 
68. Yan WL, Wang CC, Huang YD, et al. Parental factors affecting the circumcision of non-Muslim Chinese boys include education and family history. Acta Paediatr. 2015;104(12):e569-76.

69. Qian HZ, Ruan Y, Liu Y, et al. Lower HIV risk among circumcised men who have sex with men in China: Interaction with anal sex role in a cross-sectional study. J Acquir Immune Defic Syndr. 2016;71(4):444-51.

70. The DHS Program. Demographic and Health Surveys, Comoros, 2012. Table 14.13. 2012. http://dhsprogram.com/pubs/pdf/FR278/FR278.pdf. Accessed 4 Jul 2014.

71. The DHS Program. Demographic and Health Surveys, Républic Démocratic du Congo, 2007. Table 14.12. 2008. http://dhsprogram.com/pubs/pdf/ FR208/FR208.pdf. Accessed 16 Sep 2015.

72. The DHS Program. Demographic and Health Surveys. Cote d'Ivoire. 20112012. Table 13.13. 2013. http://dhsprogram.com/pubs/pdf/FR272/FR272.pdf. Accessed 14 Mar 2014.

73. Sassan-Morokro M, Greenberg AE, Coulibaly IM, et al. High rates of sexual contact with female sex workers, sexually transmitted diseases, and condom neglect among HIV-infected and uninfected men with tuberculosis in Abidjan, Cote d'Ivoire. J Acquir Immune Defic Sydnr Hum Retrovirol. 1996; 11(2):183-7.

74. Svare El, Kjaer SK, Worm AM, et al. Risk factors for genital HPV DNA in men resemble those found in women: a study of male attendees at a Danish STD clinic. Sex Transm Infect. 2002;78:215-8.

75. The DHS Program. Demographic and Health Surveys, República Dominicana, 2007. Table 12.14. 2008. http://dhsprogram.com/pubs/pdf/ FR212/FR212.pdf. Accessed 4 Jul 2014

76. Brito MO, Caso LM, Balbuena H, Bailey RC. Acceptability of male circumcision for the prevention of HIV/AIDS in the Dominican Republic. PLoS One. 2009;4(e7687):1-6.

77. The DHS Program. Demographic and Health Surveys, Ethiopia, 2011. 2012. http://dhsprogram.com/pubs/pdf/FR255/FR255.pdf. Accessed 14 Mar 2014

78. Kolehmainen M, Taskinen S, Ossi L. Foreskin surgery. Duodecim; laaketieteellinen aikakauskirja. 2010;126(1):75-83.

79. United Nations High Commissioner for Refugees. Behavioural Surveilance Surveys Among Refugees and Surrounding Host Population, Kakuma, Kenya. 2004. http://www.unhcr.org/441fcc062.html. Accessed 24 Jun 2014.

80. Manix. Circoncision. http://www.manix.net/enjoy/sex-news/sex-stat-1/index. $\mathrm{cfm} ? \mathrm{i}=1132$. Accessed 18 Feb 2014

81. The DHS Program. Demographic and Health Surveys, Gabon. 2012. Table 3. 10. 2013. http://dhsprogram.com/pubs/pdf/FR276/FR276.pdf. Accessed 14 Mar 2014

82. Kamtsiuris $P$, Bergmann E, Rattay $P$, Schlaud M. Use of medical services. Results of the German Health Interview and Examination Survey for Children and Adolescents (KiGGS). Bundesgesundheitsblatt Gesundheitsforschung Gesundheitsschutz. 2007;50:836-50.

83. Hoschke B, Fenske S, Brookman-May S, et al. Male circumcision is not associated with an increased prevalence of erectile dysfunction: Results of the Cottbus 10,000-men survey]. (Article in German) Urologe A. 2013;52:562-9.

84. The DHS Program. Demographic and Health Surveys, Ghana. 2008. 2009. http://dhsprogram.com/pubs/pdf/FR221/FR221\%5B13Aug2012\%5D.pdf. Accessed 14 Mar 2014.

85. The DHS Program. Demographic and Health Surveys, Equatorial Guinea, 2011. Table 14.5. 2012. http://dhsprogram.com/pubs/pdf/FR271/FR271.pdf. Accessed 5 Aug 2014.

86. The DHS Program. Demographic and Health Surveys, Guyana 2009. Table 13.11. 2010. http://dhsprogram.com/pubs/pdf/FR232/FR232.pdf. Accessed 18 Oct 2015.

87. Wang Z, Lau JT, Gu J. Acceptability of circumcision among clients of female sex worker in Hong Kong. AIDS Behav. 2012;16:1836-45.

88. Reynolds SJ, Shepherd ME, Risbud AR, et al. Male circumcision and risk of HIV-1 and other sexually transmitted infections in India. Lancet. 2004:363:1039-40.

89. Schneider JA, Dandona R, Pasupneti S, et al. Initial commitment to pre-exposure prophylaxis and circumcision for HIV prevention amongst Indian truck drivers. PLoS One. 2010;5:e11922.

90. Madhivanan P, Krupp K, Kulkarni V, et al. Acceptability of male circumcision for HIV prevention among high-risk men in Pune. India Sex Transm Dis. 2011;38:571.

91. Prem Kumar SG, Kumar GA, Poluru R, et al. Contact with HIV prevention programmes \& willingness for new interventions among truckers in India. Indian J Med Res. 2013;137:1061-71.
92. Figueroa JP, Cooper CJ. Attitudes towards male circumcision among attendees at a sexually transmitted infection clinic in Kingston, Jamaica. West Indian Med J. 2010;59:351-5.

93. Walcott MM, Jolly PE, Ehiri JE, et al. Factors associated with the acceptability of male circumcision among men in Jamaica. PLoS One. 2013;8(e75074):1-11.

94. Yamagishi $\mathrm{T}$, Imai H, Nakao H, et al. Inter-rater reliability of self-reported response on foreskin status in questionnaire among Japanese adult men. Sex Transm Infect. 2012:88:534-8.

95. The DHS Program. Demographic and Health Surveys, Kenya, 2008-09. Table 13.11. 2010. http://dhsprogram.com/pubs/pdf/FR229/FR229.pdf. Accessed 5 Aug 2014.

96. Maina WK, Kim AA, Rutherford GW, et al. Kenya AIDS Indicator Surveys 2007 and 2012: implications for public health policies for HIV prevention and treatment. J Acquir Immune Defic Syndr. 2014;66 Suppl 1:S130-7.

97. Lavreys L, Rakwar JP, Thompson ML, et al. Effect of circumcision on incidence of human immunodeficiency virus type 1 and other sexually transmitted diseases: a prospective cohort study of trucking company employees in Kenya. J Inf Dis. 1999;180:330-6.

98. Ku JH, Kim ME, Lee NK, Park YH. Circumcision practice patterns in South Korea: community based survey. Sex Transm Infect. 2003;79(1):65-7.

99. Shin H-R, Franceschi S, Vaccarella S, et al. Prevalence and determinants of genital infection with papillomavirus, in female and male university students in Busan, South Korea. J Infect Dis. 2004;190:468-78.

100. Kim D, Koo SA, Pang MG. Decline in male circumcision in South Korea. BMC Public Health. 2012;12(1067):1-7.

101. Pang MG, Kim DS. Extraordinary high rates of male circumcision in South Korea: history and underlying causes. BJU Int. 2002:89:48-54.

102. Demographic and Health Surveys, Kyrgyz Republic, 2012. Table 13.14. 2013. http://dhsprogram.com/pubs/pdf/FR283/FR283.pdf. Accessed 5 Aug 2014.

103. Coburn BJ, Okano JT, Blower S. Current drivers and geographic patterns of HIV in Lesotho: implications for treatment and prevention in Sub-Saharan Africa. BMC Med Res Methodol. 2013;11(224):1-11.

104. The DHS Program. Demographic and Health Surveys, Lesotho, 2009. Table 12. 11. 2010. http://pdf.usaid.gov/pdf_docs/PNADU407.pdf. Accessed 5 Aug 2014.

105. The DHS Program. Demographic and Health Surveys, Lesotho, 2014. Table 3.20. 2015. http://dhsprogram.com/pubs/pdf/PR62/PR62.pdf. Accessed 18 Oct 2015.

106. The DHS Program. Demographic and Health Surveys, Liberia, 2007. Table 13 11. (accessed Aug 5, 2014). 2008. http://dhsprogram.com/pubs/pdf/FR201/ FR201.pdf. Accessed 14 Apr 2014

107. The DHS Program. Demographic and Health Surveys, Liberia, 2013. Table 13.13. 2014. http://dhsprogram.com/pubs/pdf/FR291/FR291.pdf. Accessed 18 Oct 2015.

108. The DHS Program. Demographic and Health Surveys, Madagascar, 2008-09. Table 3.3. 2010. http://www.instat.mg/pdf/eds2008-2009.pdf. Accessed 15 Apr 2014

109. College of Medicine Malawi. Situation analysis of male circumcision in Malawi (from Malawai Demographic and Health Survey 2004). Table 5. 2010 http://www.k4health.org/toolkits/malawi-hivaids/situation-analysis-malecircumcision-malawis. Accessed 15 Apr 2014.

110. Mkandawire $P$, Luginaah I, Dixon J, et al. Circumcision status and time to first sex among never-married young men in Malawi: evidence from the demographic and health survey. AIDS Behav. 2013;17:2123-35.

111. The DHS Program. Demographic and Health Surveys, Malawi, 2010. Table 13.11. 2011. http://dhsprogram.com/pubs/pdf/FR247/FR247.pdf. Accessed 15 Apr 2014.

112. Malawi BB. Malawi Biological and Behavioural Surveillance Survey 2006 and Comparative Analysis of 2004 BBS and 2006 BBSS. http://www.k4health.org/ sites/default/files/MALAWI BBSS 2006 optimized .pdf (accessed Apr 15, 2014). 2006

113. Diallo S, Toloba Y, Coulibaly SA, et al. Male circumcision and HIV in the Malian military. Mali Med. 2008:23:45-6.

114. The DHS Program. Demographic and Health Surveys, Mozambique, 2011. Table 13.13. http://dhsprogram.com/pubs/pdf/FR266/FR266.pdf (Accessed Apr 15, 2014). 2013.

115. The DHS Program. Demographic and Health Surveys, Namibia, 2006-07. Table 14.12. http://dhsprogram.com/pubs/pdf/FR204/FR204c.pdf (Accessed Apr 15, 2014). 2008

116. United Nations High Commissioner for Refugees. HIV and AIDS Behavioural Surveillance Survey, Osire refugee camp and surrounding communities Namibia. http://www.unhcr.org/4b5eeb259.html(accessed Oct 17, 2015) 
117. The DHS Program. Demographic and Health Surveys, Namibia, 2013. Table 14.11. http://www.dhsprogram.com/pubs/pdf/FR298/FR298.pdf (Accessed Oct 18, 2015). 2014.

118. Fergusson DM, Boden JM, Horwood LJ. Circumcision status and risk of sexually transmitted infection in young adult males: an analysis of a longitudinal birth cohort. Pediatrics. 2006;118:1971-7.

119. Dickson NP, Ryding J, van Roode T, et al. Male circumcision and serologically determined human papillomavirus infection in a birth cohort. Cancer Epidemiol Biomarkers Prev. 2009;18:177-83.

120. The DHS Program. Demographic and Health Surveys, Nigeria, 2013. Table 13.13. http://dhsprogram.com/pubs/pdf/FR293/FR293.pdf (Accessed Jul 4, 2014). 2013.

121. The DHS Program. Demographic and Health Surveys, Nigeria, 2008. Table 13.12. http://dhsprogram.com/pubs/pdf/FR222/FR222.pdf (Accessed Apr 15, 2014). 2009.

122. Myers RA, Omorodion Fl, Isenalumhe AE, Akenzua Gl. Circumcision: its nature and practice among some ethnic groups in southern Nigeria. Soc Sci Med. 1985;21(5):581-8.

123. Caldwell JC, Orubuloye IO, Caldwell P. Male and female circumcision in Africa from a regional to a specific Nigerian examination. Soc Sci Med. 1997:44(8):1181-93.

124. MacLaren D, Tommbe R, Mafile'o T, et al. Foreskin cutting beliefs and practices and the acceptability of male circumcision for HIV prevention in Papua New Guinea. BMC Public Health. 2013;13(818):1-17.

125. MacLaren DJ, McBride WJ, Kelly GC, et al. HIV prevalence is strongly associated with geographical variations in male circumcision and foreskin cutting in Papua New Guinea: an ecological study. Sex Transm Infect. 2015;91(7):502-5.

126. Guanira J, Lama J, Goicochea P, et al. How willing are gay men to "cut off" the epidemic? Circumcision among MSM in the Andean region. 4th International AIDS Society Conference on HIV Pathogenesis, Treatment and Prevention, Sydney, Australia 2007:WEAC102.

127. The DHS Program. Demographic and Health Surveys, Rwanda, 2010. Table 13.19. http://dhsprogram.com/pubs/pdf/FR259/FR259.pdf (accessed Apr 15, 2014). 2012.

128. McDaid LM, Weiss HA, Hart GJ. Circumcision among men who have sex with men in Scotland: limited potential for HIV prevention. Sex Transm Infect. 2010;86:404-6.

129. The DHS Program. Demographic Health Surveys, Sierra Leone, 2008. Table 13.12 http://dhsprogram.com/pubs/pdf/FR225/FR225.pdf (Accessed Apr 15, 2014). 2009.

130. Klavs I, Hamers FF. Male circumcision in Slovenia: results from a national probability sample survey. Sex Transm Infect. 2007;84:49-50.

131. Podnar S. Clinical elicitation of the penilo-cavernosus reflex in circumcised men. BJU Int. 2012;109:582-5.

132. United Nations High Commissioner for Refugees. HIV Behavioural Surveillance Survey in Dadaab Refugee Camps, Kenya. http://www.unhcr. org/4d231ca09.html (accessed Apr 15, 2014). 2010

133. Scott BE, Weiss HA, Viljoen Jl. The acceptability of male circumcision as an HIV intervention among a rural Zulu population, Kwazulu-Natal, South Africa. AIDS Care. 2005;17:304-13.

134. The DHS Program. Demographic and Health Surveys, Republic of South Africa, 2003. Table 5.17. http://dhsprogram.com/pubs/pdf/FR206/FR206.pdf (accessed Apr 15, 2014). 2007.

135. Peltzer K, Mlambo M. Prevalence and acceptability of male circumcision among young men in South Africa. Ethno Med. 2012:6:179-86.

136. United Nations High Commissioner for Refugees. HIV Behavioural Surveillance Survey Juba Municipality, South Sudan. http://www.unhcr.org/ 477cdccd2.pdf (accessed Jun 24, 2014). 2007.

137. United Nations High Commissioner for Refugees. HIV Behavioural Surveillance Survey in Kajo Keji County, Central Equatoria State, Southern Sudan. http://www.unhcr.org/4d231c079.pdf (accessed Jun 24, 2014). 2010.

138. The DHS Program. Demographic and Health Surveys, Swaziland, 2007-07. Table 12.7. http://dhsprogram.com/pubs/pdf/FR202/FR202.pdf (Accessed Apr 15, 2014). 2008.

139. Ko MC, Liu CK, Lee WK, et al. Age-specific prevalence rates of phimosis and circumcision in Taiwanese boys. J Formos Med Assoc. 2007;106:302-7

140. Tanzania HM. Tanzania HIV/AIDS and Malaria Indicator Survey (2007-08 THMIS). Table 3.9. http://tacaids.go.tz/index.php?option=com docman\&task=doc_download\&gid=77\&ltemid=142 (accessed Jun 20, 2014). 2008.
141. The DHS Program. Demographic and Health Surveys, Tanzania, 2010. Table 13.11.http://www.nbs.go.tz/takwimu/references/2010TZKeyFindings.pdf (Accessed Apr 15, 2014). 2011.

142. The DHS Program. Tanzania, 2011-12 HIV/AIDS and Malaria Indicator Survey, page 6. http://dhsprogram.com/pubs/pdf/SR196/SR196.pdf (Accessed Apr 15, 2014). 2013.

143. Mubekapi C. Knowledge, attitudes and practices of male circumcision as an HIV prevention method among males in a Mine. Geita, Tanzania: Stellenbosch, Stellenbosch University; 2013.

144. Tieu HV, Phanuphak N, Ananworanich J, et al. Acceptability of male circumcision for the prevention of HIV among high-risk heterosexual men in Thailand. Sex Transm Dis. 2010;37:352-5.

145. The DHS Program. Demographic and Health Surveys, Timor-Leste, 2009-2010. http://www.dhsprogram.com/pubs/pdf/FR235/FR235.pdf (Accessed Apr 15, 2014). 2010.

146. Kibira SP, Nansubuga E, Tumwesigye NM, et al. Differences in risky sexual behaviors and HIV prevalence of circumcised and uncircumcised men in Uganda: evidence from a 2011 cross-sectional national survey. Reprod Health. 2014;11(25):1-8.

147. The DHS Program. Demographic and Health Surveys, Uganda, 2011. Table 13.13. http://www.ubos.org/onlinefiles/uploads/ubos/UDHS/UDHS2011.pdf (Accessed Apr 15, 2014). 2012.

148. AIDS Indictor Survey, 2011, Uganda. Table 9.12. http://health.go.ug/docs/ UAIS_2011_REPORT.pdf (Accessed Apr 15, 2014). 2012.

149. Bailey RC, Neema S, Othieno R. Sexual behaviors and other HIV risk factors in circumcised and uncircumcised men in Uganda. J Acquir Immune Defic Syndr. 1999;22:294-301.

150. The DHS Program. Demographic and Health Surveys, Ukraine, 2007. Figure 3.3, page 32. http://dhsprogram.com/pubs/pdf/FR210/FR210.pdf (Accessed Apr 15, 2014). 2008.

151. Dave SS, Johnson AM, Fenton KA, et al. Male circumcision in Britain: findings from a national probability sample survey. Sex Transm Infect. 2003;79:499-500.

152. Mallon $E$, Hawkins D, Dinneen M, et al. Circumcision and genital dermatoses. Arch Dermatol. 2000;136:350-4.

153. Cathcart $P$, Nuttall $M$, van der Meulen J, et al. Trends in paediatric circumcision and its complications in England between 1997 and 2003. Br J Surg. 2006;93:885-90.

154. Thornton AC, Lattimore $S$, Delpech $V$, et al. Circumcision among men who have sex with men in London, United Kingdom: An unlikely strategy for HIV prevention. Sex Transm Dis. 2010;38:928-31.

155. Groves H, Bailie A, McCallion W. Childhood circumcision in Northern Ireland: a barometer of the current practice of general paediatric surgery. Ulster Med J. 2010;79(2):80-1.

156. Homfray V, Tanton C, Mitchell KR, et al. Examining the association between male circumcision and sexual function: evidence from a British probability survey. AIDS. 2015;29(11):1411-6.

157. Homfray V, Tanton C, Miller RF, et al. Male circumcision and STI acquisition in Britain: Evidence from a national probability sample survey. PLoS One. 2015:10(6):e0130396.

158. Maeda JL, Chari R, Elixhauser A. Circumcisions Performed in U.S. Community Hospitals, 2009: Statistical Brief \#126. Rockville (MD): Healthcare Cost and Utilization Project (HCUP) Statistical Briefs; 2006.

159. Warner L, Cox S, Whiteman $M$, et al. Impact of health insurance type on trends in newborn circumcision, United States, 2000 to 2010. Am J Public Health. 2015:105(9):1943-9.

160. The DHS Program. Demographic and Health Surveys, Zambia, 2013-14. Table 13.15. http://www.dhsprogram.com/pubs/pdf/FR235/FR235.pdf. Accessed 18 Oct 2015.

161. The DHS Program. Demographic and Health Surveys, Zambia, 2007. Table 13.12. 2009. http://dhsprogram.com/pubs/pdf/FR211/FR211\%5Brevised-0512-2009\%5D.pdf. Accessed 15 Apr 2014.

162. United Nations High Commissioner for Refugees. HIV and AIDS Behavioural Surveillance Survey, Refugee Camps and Hosting Communities in Kawambwa and Mporokoso, Zambia. http://www.unhcr.org/45e2f5ef2.html. Accessed 4 Jul 2014

163. The DHS Program. Demographic and Health Surveys, Zimbabwe, 2010-11. Table 13.13. 2012. http://dhsprogram.com/pubs/pdf/FR254/FR254.pdf. Accessed 15 Apr 2014

164. Thomas AG, Tran BR, Cranston M, et al. Voluntary medical male circumcision: a cross-sectional study comparing circumcision self-report and physical examination findings in Lesotho. PLoS One. 2011;6(e27561):1-6. 
165. Wallerstein E. Circumcision. The uniquely American medical enigma. Urol Clin North Am. 1985;12:123-32.

166. Williams N, Kapila L. Complications of circumcision. Brit J Surg 1993:80:1231-6.

167. Hutcheson JC. Male neonatal circumcision: indications, controversies and complications. Urol Clin North Am. 2004;31:461-7.

168. NOHARMM. Estimated world incidence of male circumcision complications. http://www.noharmm.org/incidenceworld.htm. Accessed 17 Feb 2014.

169. Anonymous. Immer mehr Jungen im Vorschulalter werden beschnitten. (In German) Frankfurter Allgemeine, Oct 19, 2013. http://www.faz.net/aktuell/ politik/gesundheit-immer-mehr-jungen-im-vorschulalter-werdenbeschnitten-12624967.html. Accessed 6 Oct 2014.

170. Feng X-m. English translation and commentary of: Xiao Jing - The classic of xiao by Zeng Zi (505-436 BCE). http://www.tsoidug.org/Papers/Xiao_Jing_ Comment.pdf. Accessed 4 Jul 2014.

171. Sokal DC, Li PS, Zulu R, et al. Randomized controlled trial of the shang ring versus conventional surgical techniques for adult male circumcision: safety and acceptability. J Acquir Immune Defic Syndr. 2014;65:447-55.

172. Hewett PC, Haberland N, Apicella L, Mensch BS. The (mis)reporting of male circumcision status among men and women in Zambia and Swaziland: A randomized evaluation of interview methods. PloS One. 2012;7(e36251):1-10

\section{Submit your next manuscript to BioMed Central} and we will help you at every step:

- We accept pre-submission inquiries

- Our selector tool helps you to find the most relevant journal

- We provide round the clock customer support

- Convenient online submission

- Thorough peer review

- Inclusion in PubMed and all major indexing services

- Maximum visibility for your research

Submit your manuscript at www.biomedcentral.com/submit 